\title{
THE ROLE OF ECONOMIC ANALYSIS IN SHAPING ENVIRONMENTAL POLICY
}

\author{
Arthur FraAs* \\ I \\ INTRODUCTION
}

Over the last two decades, the environment has become a major concern for all developed nations. An increasing amount of national resources is being expended to address environmental problems. Many environmental initiatives take the form of government regulation of the private activities of manufacturers and consumers. By controlling the emissions to air and water, requiring the safe disposal of wastes, and banning the use of certain substances and products, regulations can yield substantial environmental and health benefits.

Unfortunately, the regulatory actions needed to create these environmental benefits often impose substantial costs. In a typical year, the Environmental Protection Agency ("EPA") publishes several major proposed or final regulations, each of which will impose net annual economic costs ranging from half a billion to well over a billion dollars. In addition to the substantial direct costs of these rules, they may also have unintended effects that interfere with other social goals. For example, the adoption of more stringent automobile fuel economy standards will likely have adverse effects on automobile safety. Therefore, it is important to consider all the effects of proposed initiatives before imposing regulations. This will insure that regulatory actions achieve their intended objectives effectively and efficiently.

This article sets out the recent United States experience in using economic analysis to develop environmental policy. The article first outlines the role provided for economic analysis in shaping regulations under the environmental statutes of the United States. It then discusses the analytical requirements of Executive Order 12291.' Finally, the article discusses two

Copyright $\odot 1991$ by Law and Contemporary Problems

* Office of Management and Budget. Washington, D.C.

The views presented in this paper are solely the author's and do not necessarily reflect the views of the Office of Management and Budget. The author thanks Susan Mitchell, Rich Theroux, Kip Viscusi, and the editors of this journal for their comments and help on earlier drafts.

Over the last ten years, the author has been responsible for reviewing analyses for many of the EPA's major regulatory actions. He is currently chief of the Natural Resources Branch, Office of Information and Regulatory Affairs ("OIRA"), Office of Management and Budget ("OMB"). This branch reviews the regulatory and paperwork activities of the energy and environmental agencies within the federal government.

1. Executive Order 12291, signed by President Reagan in January 1981, represents the cornerstone of current executive oversight of federal regulatory activity. The Executive Order requires that federal agencies submit proposed and final rules to the OIRA (within OMB) for review 
cases in which economic analysis proved important and summarizes EPA's experience with the use of economic analysis in shaping environmental policy.

\section{The Role of Analysis under the Environmental Statutes}

All three branches of the federal government figure prominently in shaping environmental policy. First, Congress enacts the basic environmental statutes. Then, the executive branch, through EPA, interprets the general statutory language and establishes specific requirements for state and local government, industry, and individual households. After EPA promulgates regulations, interested parties may challenge its interpretation of the statute in the courts. Such challenges may succeed where EPA's action is contrary to specific statutory language or where it has made procedural errors. Typically, though, the courts give broad deference to agency rulemaking.

There is no formal role for economic analysis in developing new legislation, although interested parties often present analytical studies addressing specific issues of concern during the course of developing legislation. In addition, Congress may require EPA to conduct an economic analysis as a part of its rulemaking process, and it may also prohibit the consideration of certain kinds of analysis. Thus, EPA's discretion to use economic analysis as a basis for decisionmaking varies considerably across statutes, and even within statutes. The specific federal environmental statute in question determines the extent to which economic analysis contributes to EPA's interpretation.

In some cases, EPA has substantial latitude to use benefit/ cost (or "costeffectiveness") analysis in a variety of important programs under each of the environmental statutes. (See Table I) For example, the Clean Air Act and Clean Water Act provisions establishing "technology-based" standards to limit emissions from major industrial sources allow the consideration of a variety of factors, including the costs and cost-effectiveness of alternative requirements. ${ }^{2}$ In addition, the "unreasonable risk" language contained in key provisions of the Federal Insecticide, Fungicide, and Rodenticide Act ("FIFRA") and the Toxic Substances Control Act ("TSCA") explicitly adopts

prior to their publication in the Federal Register. Under Executive Order 12291 federal agencies are, to the extent permitted by law, to undertake regulatory action only if (1) there is adequate information concerning the need for and consequences of the proposed action and (2) the proposed action maximizes net benefits to society. 3 CFR $\S 103$ (1982).

2. These include New Source Performance Standards under section 111 of the Clean Air Act, Publ L No 91-604, 84 Stat 1683 (1970), now codified as amended at 42 USC $\$ \S 7407,7411$ (1988) and the effluent guideline requirements under sections 301,304 , and 307 of the Clean Water Act, Publ L 92.500, 86 Stat 816 (1972), now codified at 33 USC $\S \S 1311,1314,1317$. For a further discussion of the use of a "cost-effectiveness" criterion in setting technology-based limits under the Clean Water Act, see Arthur Fraas \& V. G. Munley, Economic Objectives within a Bureaucratic Decision Process: Setting Pollution Control Requirements under the Clean Water Act, J Envir Econ \& Mgmt 17, 35-53 (1989). 


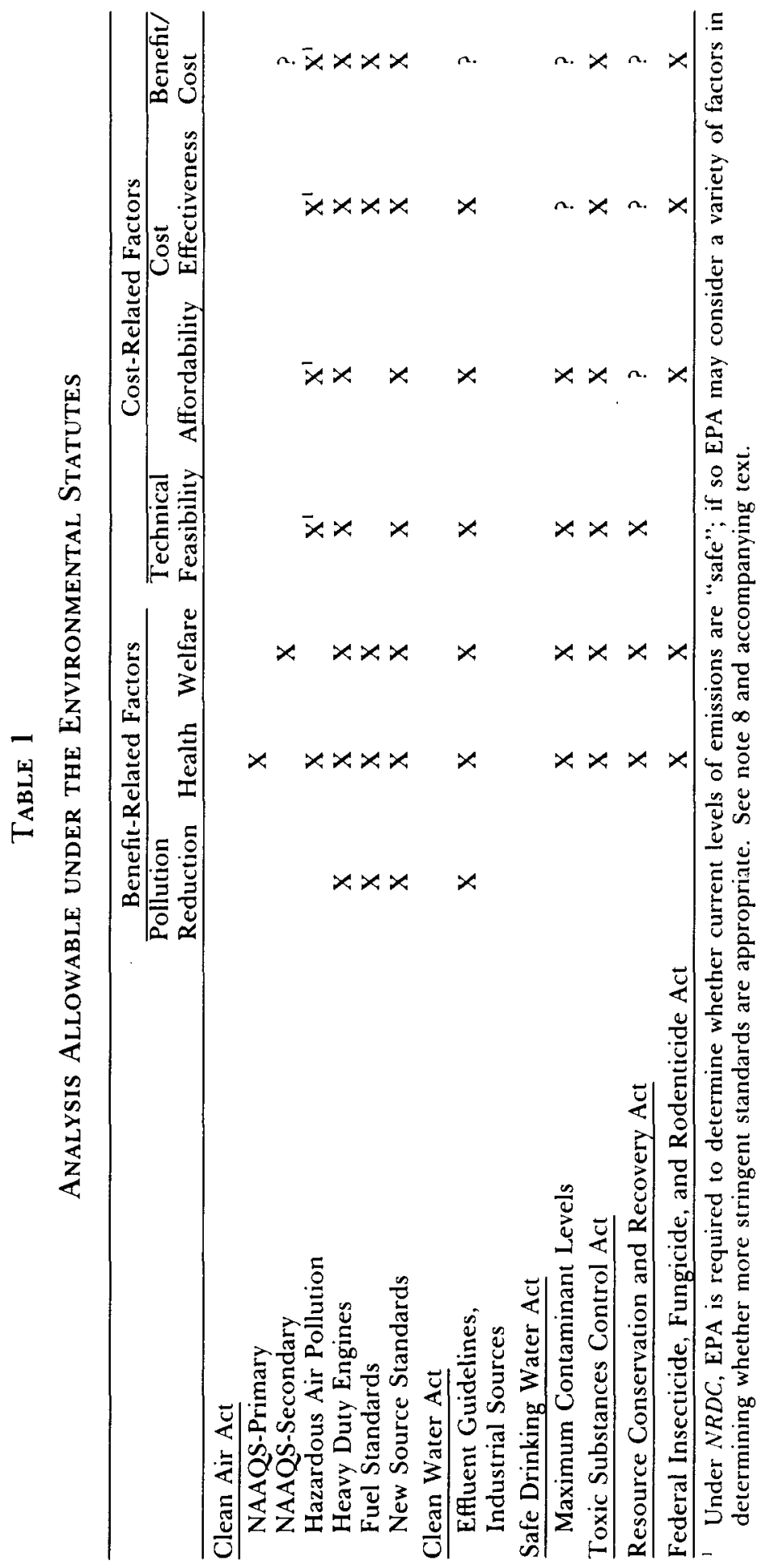


a benefit/cost framework as a basis for decisionmaking. ${ }^{3}$ Where EPA has this flexibility, economic analysis can play an important role in setting regulatory policy. Statutory provisions directed at the protection of public health, however, often restrict EPA's discretion in using such analysis. For example, the Clean Air Act requires that EPA establish primary National Ambient Air Quality Standards ("NAAQS") for the "criteria" pollutants so that they protect public health with an adequate margin of safety. 4 EPA has interpreted this provision as requiring that the primary NAAQS are to be set solely on the basis of the effects of these pollutants on health. Other factors, such as the feasibility or cost of achieving these standards, cannot be considered. 5 This interpretation was upheld by the D.C. Circuit Court of Appeals. ${ }^{6}$

Over the last decade, Congress and the courts have acted to limit federal regulators' discretion and the use of economic analysis in making regulatory decisions addressing public health. In 1986, Congress amended the Safe Drinking Water Act by replacing the original language that allowed the consideration of benefits and costs in setting the maximum contaminant levels ("MCLs") for drinking water. Under the 1986 amendments, EPA must set MCLs based on the best available control technology that is "feasible." 7 As a part of this new statutory language, Congress specifically defined granular activated carbon as the best available feasible technology for controlling organic contaminants, ending a long-standing debate about requiring such technology based on benefit/cost considerations.

The 1990 Clean Air Act Amendments further limit the role of benefit/cost analysis in regulating emissions of air toxics. ${ }^{8}$ Title III of the 1990 amendments requires EPA to establish air toxic standards that represent the "maximum degree of reduction in emissions . . taking into consideration the cost of achieving such emission reduction, and any non-air quality health and environmental impacts and energy requirements. ..."9 The amendments to

3. Federal Insecticide, Fungicide, and Rodenticide Act, 7 USC $\$ 136$ (bb) (1988); Toxic Substances Control Act, 15 USC $\S 2605$ (c) (1988).

4. Clean Air Act, 42 USC $\$ 7408$.

5. Roger W. Findley \& Daniel A. Farber, Environmental Law in a Nutshell 75 (West 1988).

6. Lead Industries Association, Inc. $v$ EPA, 647 F2d 1130 (DC Cir 1980).

7. Safe Drinking Water Act, 42 USC $\$ 300 \mathrm{~g}-1(\mathrm{~b})(5)$ (1988).

8. 1990 Clean Air Act Amendments, Pub L No 101-549, 104 Stat 2399 (1990). In a 1987 decision, the D.C. Circuit interpreted the Clean Air Act provision limiting emissions of hazardous air pollutants as establishing a two-step regulatory process. As a first step, EPA was to determine whether existing emission levels were "safe." The court explicitly stated that "safe" does not mean "risk-free." If levels were not "safe," then EPA was to set emission standards that were "safe." As a second step, EPA was to determine whether a more stringent emission standard was appropriate, taking into account such factors as the feasibility of achieving these more stringent standards, the likely additional reduction in risks, and the costs of achieving this reduction. NRDC $v$ United States $E P A, 824$ F2d 1146 (DC Cir 1987) (en banc). EPA implemented this decision in setting standards for benzene and radionucleide sources by adopting as a presumptive goal (reflecting a safe level of emissions) an individual lifetime risk to the most exposed individual of one in 10,000. As a practical matter, since most industrial facilities pose maximum individual risks that are less than one in 10,000 , EPA standard-setting for air toxics under the 1987 decision would have allowed consideration of a wide variety of factors, including benefits and cost.

9. 1990 Clean Air Act Amendments $\$ 301,104$ Stat at 2399, amending $\S 112(d)(2)$ of the Clean Air Act. 
section 112(d)(3) of the original act sharply limit the discretion available under this provision by requiring that standards for new and existing sources be at least as stringent as the average performance for the best 12 percent of the existing sources. Section 112(f), as amended, envisions much more radical standard-setting. The amended section requires the EPA administrator to report to Congress any. remaining air pollution-related health hazards by 1996. If Congress does not act on any of the administrator's recommendations, the administrator is to formulate new rules ensuring "an ample margin of safety to protect public health." 10 Specifically, if the standards enacted under the initial phase of the 1990 amendments do not reduce the cancer risk to the most exposed individual from a given category to below one in one million, the administrator is to promulgate new standards for that category. ${ }^{11}$ This presumptive health goal would require emission reductions to achieve a risk level that is two orders of magnitude lower than the risk levels allowable under EPA's 1989 interpretation of NRDC $v$ United States EPA. ${ }^{12}$

\section{III}

\section{The Role of Analysis under Exegutive Order 12291}

Federal regulation has emerged as such an important and expensive part of federal activity that each of the last five presidents has established programs to review federal regulatory initiatives. The current program is based on Executive Order 12291, issued by President Reagan in February 1981. ${ }^{13}$ Under Executive Order 12291, federal agencies like EPA must show that (1) there is adequate information concerning the need for and consequences of the proposed action, and (2) to the extent permitted by law, the proposed action will maximize net benefits to society as compared to all available alternatives. ${ }^{14}$

For "major" rules, Executive Order 12291 also requires agencies to prepare a formal economic analysis-called a Regulatory Impact Analysis ("RIA")—of its selected action and reasonably available alternatives. Major rules are defined as rules with benefits or costs in excess of $\$ 100$ million per year; a major increase in costs or prices for a particular sector, industry, or region of the economy; or significant adverse effects on competition, investment, productivity, or the ability of U.S.-based firms to compete in international markets. ${ }^{15}$ Executive Order 12291 requires that RIAs contain:

(1) a description of the potential benefits of the rule, with a discussion of any benefits that cannot be quantified in monetary terms;

\footnotetext{
10. Id (amending $\S 112(0)$.

11. Id.

12. 824 F2d 1146.

13. 3 CFR \$ 127 (1982).

14. Id at $\$ 128$.

15. Id at $\$ 127$
} 
(2) a description of the potential costs of the rule, with a discussion of any adverse effects that cannot be quantified in monetary terms; and

(3) a description of alternative approaches that could achieve substantially the same goal at lower cost, with an analysis of the benefits and costs of such approaches. ${ }^{16}$

The primary purpose of the RIA is to provide decisionmakers with the best information available on the likely effects of a major rule. The RIA also provides the public, Congress, and the courts with a better understanding of the basis for agency decisionmaking.

The current Executive Order represents a major change in the role of analysis in developing environmental policy by shifting the focus from cost and "affordability" to a benefit/cost criterion. Prior to 1981, EPA prepared only a cost analysis when developing major rules. Executive Order 12291 requires an analysis of the benefits of alternative regulatory action as well.

Finally, Executive Order 12291 provides for oversight by the Executive Office of the President by requiring federal agencies to submit all proposed and final rules, including major rules and their associated RIAs, to the Office of Management and Budget ("OMB") before they are published in the Federal Register. ${ }^{17} \mathrm{OMB}$ then has the dual responsibility of (1) ensuring that draft rules are consistent with the basic principles and policy objectives of the federal government and (2) providing a measure of quality control on the RIAs prepared by the regulatory agencies. ${ }^{18}$ To meet this second responsibility, OMB can request additional analysis or the development of estimates for an alternative approach. OMB can even return a rule to its originating agency if the RIA has not been completed or appears to be seriously deficient. ${ }^{19}$ As a practical matter, though, the return of a major rule because of an inadequate RIA rarely occurs.

EPA published an increasing number of proposed and final major rules during the 1980s. In the early years of the Reagan Administration, EPA published only three to five major proposed and final rules per year. In the last two years of the Reagan Administration, EPA published roughly twenty proposed and final major rules a year. The present value costs of the rules published each year also increased substantially over the Reagan years. (See Table 2)

EPA prepared RIAs for roughly 80 percent of these rules. In those cases where EPA failed to prepare an RIA, five rules were submitted to OMB under court-ordered deadlines; an additional five rules were either withdrawn by

16. Id at $\S 129$.

17. Id at $\S \S 128-29$.

18. Id at $\S 131$.

19. In 1990, for example, OIRA returned EPA's proposed rule setting effluent limits for discharges of water from offshore oil and gas production because of the inadequacy of the supporting analysis. Letter to EPA Administrator William K. Reilly from Acting OIRA Administrator James B. MacRae, Jr., Nov 16, 1990 (On file in OIRA docket library). 
TABLE 2

Summary of Action on Major EPA Rules, 1981-1990

\begin{tabular}{|c|c|c|c|c|c|c|c|c|c|}
\hline & 1981 & $\underline{1982}$ & 1983 & 1984 & $\underline{1985}$ & 1986 & 1987 & 1988 & 1989 \\
\hline $\begin{array}{l}\text { Review Concluded } \\
\text { within Court Deadline }\end{array}$ & 0 & 0 & 1 & 0 & 0 & 0 & 8 & 7 & 6 \\
\hline Withdrawn & 0 & 1 & 1 & 2 & 1 & 0 & 1 & 2 & 1 \\
\hline Returned & 0 & 0 & 0 & 0 & 0 & 0 & 0 & 2 & 0 \\
\hline Suspended & 0 & 0 & $\mathbf{0}$ & 0 & 0 & 0 & 0 & 1 & 1 \\
\hline $\begin{array}{l}\text { Conclusion of Review as } \\
\text { Consistent with } \\
\text { Executive Order }\end{array}$ & 3 & 4 & 3 & 6 & 11 & 6 & 12 & 6 & 4 \\
\hline Total Major Rules & 3 & 5 & 5 & 8 & 12 & 6 & 21 & 18 & 12 \\
\hline $\begin{array}{l}\text { Present Value Cost of } \\
\text { Major Final Rules } \\
\text { (Billion 1988 \$) }\end{array}$ & $\begin{array}{c}\text { Not } \\
\text { available }\end{array}$ & 2 & 2 & None & 18 & 2 & 20 & 84 & 6 \\
\hline
\end{tabular}

Source: OMB Office of Information and Regulatory Affairs records (on file with author).

\section{TABLE 3}

EPA Major Rules and Regulatory Impact ANAlysis 1981-1990

\begin{tabular}{lcccccccccc}
\hline & 1981 & $\frac{1982}{1}$ & $\frac{1983}{5}$ & $\frac{1984}{8}$ & $\frac{1985}{12}$ & $\frac{1986}{4}$ & $\frac{1987}{18}$ & $\frac{1988}{12}$ & $\frac{1989}{9}$ & $\frac{\text { Total }}{74}$ \\
$\begin{array}{l}\text { Rules with RIA } \\
\text { Rules without RIA }\end{array}$ & 0 & 0 & 0 & 0 & 0 & 2 & 3 & 6 & 3 & 14 \\
$\begin{array}{l}\text { Total Major Rules } \\
\text { Received }\end{array}$ & 3 & 5 & 5 & 8 & 12 & 6 & 21 & 18 & 12 & 90 \\
\hline
\end{tabular}

Source: OMB Office of Information and Regulatory Affairs records (on file with author).

1 There is no record concerning whether RIAs were submitted with two major rules in 1981.

EPA or returned to EPA for reconsideration by OMB. ${ }^{20}$ Even where EPA did not prepare a formal RIA, it often developed an analysis of the costs (and in some cases the benefits) for the draft rule.

The RIAs prepared by EPA focused on developing a benefit/cost analysis of the selected regulatory requirements and reasonable alternatives. ${ }^{21}$ In some cases, the RIAs considered additional issues critical to the design of effective regulations, such as the appropriate level of government intervention (federal versus state or local action) and the nature of the intervention (for example, technology-specific requirements versus performance standards or other economic incentive approaches that allow plant operators greater discretion in determining the best means of complying with the standard).

The quality of the RIAs prepared by EPA has been decidedly mixed. In some important cases, economic analysis has shaped environmental regulation. Often, though, the RIAs have been inadequate to support critical regulatory decisions. For example, some RIAs have given only a qualitative statement of the likely benefits of the selected option, without any quantitative

20. No explanation for EPA's failure to provide RIAs for four other rules is available.

21. EPA's RIAs have typically given only brief attention, though, to whether government intervention is needed because environmental problems arise from market failure. 
estimate of the benefits for comparison to the expected costs of the proposed regulatory action. Where benefits have been quantified, the large range in the projected benefits and the qualifications surrounding these estimates have often made it difficult to use the results in making policy decisions. ${ }^{22}$

The inconsistent quality of EPA's RIAs and the failure of EPA to prepare RIAs for some major rules reflect, in part, an increasing pressure on EPA to proceed with rulemaking under very stringent statutory and judicial deadlines. These deadlines often do not permit the development of a regulatory analysis adequate to support the rule. However, when economic analysis has been done correctly, and in detail, it has greatly aided in shaping environmental regulations. The discussion below outlines two cases that demonstrate this.

\section{IV}

\section{Case Studies}

A. Phasedown of Lead in Gasoline

EPA has regulated lead in gasoline since 1973 . The 1973 regulation was motivated primarily by the need to assure the availability of unleaded gasoline for cars equipped with catalytic converters. In 1974, EPA required new cars and light duty trucks to have catalytic converters to meet the Clean Air Act emission standards. ${ }^{23}$ Leaded gasoline poisons the catalyst, making the catalytic converter ineffective in controlling hydrocarbon and carbon monoxide emissions. Furthermore, in order to reduce population exposure to lead, EPA established a limit on the total lead used in gasoline. ${ }^{24}$

In 1981, under a new administration, EPA began a review of the limits on lead in gasoline. This review was motivated by claims from the refining industry that these limits imposed substantial costs on the industry (estimated to be as high as $\$ 1$ billion per year). While undertaking this review and developing the associated RIA, however, EPA was able to show a strong correlation between the decline in the use of lead in gasoline during the late 1970 s and the decline in blood-lead levels for urban populations. ${ }^{25}$ As a result, EPA promulgated new rules in 1982 to limit the amount of lead used in leaded gasoline rather than relaxing the limits, as the refining industry had hoped. ${ }^{26}$ Still, the allowable level of lead in gasoline remained relatively high-1.1 grams per leaded gallon.

This health evidence also led to an extensive review of the benefits of further reductions in lead use; the resulting analysis showed that a substantial

22. Even incomplete RIAs, though, often provide substantial information and a more systematic basis for evaluating regulatory alternatives.

23. 40 CFR $\$ 85$ (1974), promulgated in accordance with the Clean Air Act $\S 6(a), 84$ Stat at 1691 (1970), codified at 42 USC $\$ 7521$ (1988)

24. 40 CFR $\$ 80.20$ (1974).

25. Costs and Benefits of Reducing Lead in Gasoline: Final Regulatory Impact Analysis I20 (EPA, 1985) ("Final Lead RIA").

26. 40 CFR $\$ 80.20$ (1983). 
further reduction in lead levels in gasoline would yield substantial net social benefits. (See Table 4) These benefits were associated with three separate benefit categories. First, the RIA identified substantial health benefitsreduced medical and compensatory education costs-resulting from a reduction in blood-lead levels of inner-city children. ${ }^{27}$ Second, EPA determined that reducing the lead content of leaded gasoline would make it more expensive, cutting down the incidence of misfueling and the associated poisoning of automobile catalytic converters. ${ }^{28}$ The RIA estimated indirect benefits of $\$ 1.1$ billion (present value) from the decrease in hydrocarbon and nitrogen oxide emissions from cars and trucks. Finally, the RIA found that reducing lead in gasoline would yield a substantial reduction in operating and maintenance costs for cars and trucks. ${ }^{29}$ The estimated aggregate benefits of $\$ 8.5$ billion (present value) from a phasedown of lead in gasoline substantially exceeded the estimated social costs of $\$ 2.6$ billion (present value).

\section{TABLE 4}

\section{Present Value of Costs and Benefits of Final Rule for Phasedown of Lead in Gasoline, 1985-1992 \\ (IN Millions of 1983 Dollars)}

\begin{tabular}{lr}
\hline $\begin{array}{l}\text { Monetized Benefits } \\
\text { Children's health effects } \\
\text { Conventional pollutants, partial } \\
\text { reduction in misfueling }\end{array}$ \\
$\begin{array}{lr}\text { Maintenance } \\
\text { Fuel economy }\end{array}$ & 2,500 \\
& 1,100 \\
Total Monetized Benefits & 8,100 \\
Total Refining Costs & 8,500 \\
\hline Net Benefits & 2,600 \\
\hline Source: EPA, Costs and Benefits of Reducing Lead in Gasoline: \\
\multicolumn{2}{l}{ Final Regulatory Impact Analysis VIII 26 (Table VIII 8) } \\
$\quad$ (1985).
\end{tabular}

As a part of its RIA, EPA also examined a variety of alternative approaches, including the continued use of marketable permits, the banking of credits, and pollution charges. EPA's analysis showed that the extension of the marketable permits program begun in 1982 would offer only small benefits under the more stringent proposed rule, ${ }^{30}$ but a program that allowed refiners to "bank" lead emission credits could yield roughly $\$ 200$ million in cost savings. ${ }^{31}$ At the same time, a banking program would provide

27. Final Lead RIA IV47-53 (cited in note 25).

28. Id at VIl.

29. Id at VIII7.

30. Id at I20.

31. Id at 1165 . Refiners could generate the "banked" credits by reducing lead in their gasoline ahead of the scheduled phasedown. These credits could be used at the end of the phasedown period to "cushion" the stringent final lead limit of 0.1 grams per leaded gallon. Although the pattern of 
refiners with a measure of insurance against unforeseen events. On the basis of this analysis, EPA adopted a banking program as a part of its final rule. ${ }^{32}$

In summary, EPA revised its rules in two steps. The initial rule capped lead in leaded gasoline at 1.1 grams per gallon in 1982. Based on the results of the completed analysis, a second rule, promulgated in 1985, required a further sharp reduction to 0.1 grams per leaded gallon by January $1,1986 .^{33}$ Thus the information developed as a part of EPA's regulatory analysis resulted in a reversal of EPA's original intention-EPA decided to tighten rather than relax restrictions on gasoline lead content.

\section{B. EPA's Ban/Phaseout of Asbestos}

In 1984, EPA developed draft proposed rules that would have banned five asbestos-containing products at the end of one year and phased out the use of asbestos in all remaining products over a ten-year period. EPA's supporting draft RIA suggested substantial net benefits from a total ban/phaseout, but this analysis was initially based only on an analysis of groups of products. ${ }^{34}$ EPA's revised analysis, done on a product-by-product basis, suggested that the costs and benefits of a ban/phaseout varied widely across individual products depending on the availability of substitutes and the use of the asbestos product. ${ }^{35}$ While a ban/phaseout for some asbestos products appeared to yield cost-effective reductions in risk, a ban of other product categories would have yielded estimated costs in excess of $\$ 100$ million per statistical cancer avoided. ${ }^{36}$ As a result, this proposal raised as a critical issue the appropriateness of a complete phaseout of the use of asbestos.

Over the next few years, EPA substantially revised the estimated health benefits and costs of a ban/phaseout, but a substantial variation in health benefits and costs across product categories remained. (See Table 5) EPA's data suggested that the ban/phaseout of a subset of product categories would achieve most of the benefits at a fraction of the cost of a complete ban/phaseout.

On the basis of this analysis, EPA promulgated a final rule in 1989 phasing out asbestos use in twenty-seven product categories over a seven-year period. ${ }^{37}$ The phaseout is to occur in three stages: the ban on the first group

lead usage over the phasedown period might be somewhat different under a banking program, total lead usage over the phasedown period would remain the same. Id at II60-61.

32. Id.

33. 40 CFR $\$ 80.20$ (1986).

34. Preliminary Regulatory Impact and Regulatory Flexibility Analysis of the Proposed Revisions to the Standard for Regulating Occupational Exposure to Asbestos V29-54 (EPA, 1984).

35. Final Regulatory Impact and Regulatory Flexibility Analysis of the Revised Asbestos Standard, Parts V \& VI (EPA, 1986) ("Final Asbestos RIA").

36. EPA estimated that costs of the ban would range from roughly $\$ 60,000$ per cancer avoided with a ban of asbestos cloth to over $\$ 650$ million for the one statistical cancer avoided with the phaseout of asbestos brake blocks. There was almost no additional reduction in cancer risk with the ban/phaseout of nine additional small product categories. However, a phaseout of these categories would have imposed net social costs of roughly $\$ 150$ million. Final Asbestos RIA V1 (cited in note 35).

37. 40 CFR $\S 763.160-703.179(1990)$. 
TABLE 5

Present Value of Costs and Benefits of the Ban/Phasedown of Asbestos Use in Products, 1987-2000

\begin{tabular}{lccc}
$\begin{array}{c}\text { Major Categories Subject to } \\
\text { Ban /Phasedown }\end{array}$ & $\begin{array}{c}\text { Total } \\
\text { Cancers } \\
\text { Avoided }\end{array}$ & $\begin{array}{c}\text { Benefits with } \\
\text { Continued Use } \\
\text { (Present Value) }\end{array}$ & $\begin{array}{c}\text { Cost per Statistical } \\
\text { Cancer Avoided } \\
\text { (Millions \$/Case) }\end{array}$ \\
\hline Beater/A Gaskets & 21.0 & 110.0 & 5.2 \\
Roofing Felt & 1.2 & 7.3 & 6.1 \\
Sheet Gaskets & 11.0 & 97.0 & 8.8 \\
Roof Coatings & 1.1 & 45.0 & 40.0 \\
A/C Pipe & 2.1 & 128.0 & 61.0 \\
A/C Sheet & 0.9 & 2.4 & 2.7 \\
A/C Shingles & 0.2 & 24.0 & 120.0 \\
Drum Brake Linings & 6.3 & 7.1 & 1.1 \\
Drum After Market & 77.0 & 8.8 & 0.1 \\
Disc Brake Pads & 0.9 & 3.9 & 4.3 \\
Disc Aftermarket & 12.0 & 3.9 & 0.3 \\
Brake Blocks & 7.3 & 2.0 & 0.3 \\
Major & & & \\
Exempted Categories & & & 7000 \\
Asbestos Diaphragms & 0.3 & 2000 & $>125$ \\
Hi-Grade Electrical Tape & 0.4 & $>50$ & 90 \\
Missile Liners & 0.4 & 2000 & 350 \\
Reinforced Plastic & 0.4 & 35 & 15 \\
Sealant Tape & 6.1 & 35 & 95 \\
Special Industrial Gaskets & 6.6 & 95 & \\
\hline
\end{tabular}

Source: EPA, Asbestos: Manufacture, Importation, Processing, and Distribution in Commerce Prohibitions, 54 Fed Reg 29460, 29460-29507 (1989).

' In millions of dollars. Discounted at $3 \%$ from time of exposure; EPA did not discount over the latency period.

2 Discounted at $3 \%$; costs based on 1987 dollars.

of products begins in August 1990; a ban for a second group in 1993; and a ban for the final group in 1996. ${ }^{38}$ At the same time, EPA exempted ten product categories from the phaseout. The product categories exempted represent a set of highly-valued uses in industrial, space, and military applications where the development of suitable substitutes remains uncertain. Together, the exempted categories represent roughly 5 percent of current asbestos use in the United States. EPA estimated that the continued use of asbestos in these product categories would result in only a small increase in cancer risks, while the costs of a ban would be at least several billion dollars. ${ }^{39}$ Using EPA's estimates, this approach achieves a 95 percent reduction in the cancer incidence associated with the use of asbestos in products at only 10 percent of the cost of a total ban/phaseout.

38. 40 CFR $\& 763.165$.

39. The health risks associated with these exempted uses appear to be quite small because (1) the volume of asbestos used in these products is very small, (2) uses are limited to industrial and military applications so that exposures over product lifecycle are limited, and (3) continuing OSHA regulation will further limit occupational exposure. 


\section{Caveat Emptor}

Despite the thoroughness of these two RIAs, there were still important flaws in the analyses. In the lead phasedown case, important cost and benefit categories were not quantified. EPA based its health-benefit estimates of reducing blood-lead levels solely on the cost of remedial health and education care for children with elevated levels; there may be additional health benefit categories to be considered.40 On the other hand, EPA may have overstated actual benefits from some benefit categories. For example, EPA estimated that the reduction in operation and maintenance costs with lead phasedown substantially exceeded the expected refining cost. There is little evidence from the private market to support these estimates. Certainly, if the net benefit accruing to vehicle owners from using unleaded gas were as large as projected by EPA, we would have expected to see drivers shifting from leaded to unleaded gasoline as soon as unleaded gasoline was offered in the mid1970 s. ${ }^{41}$

In its decision regarding asbestos products, EPA argued that its analysis did not estimate accurately the increase in actual exposure to the general population from continued asbestos use. ${ }^{42}$ EPA also argued that the RIA overstated the costs of a ban/phasedown because it made conservative assumptions about the cost of substitutes. ${ }^{43}$ EPA did not acknowledge, though, that other assumptions in its analysis probably overstated actual health risks. For example, EPA's analysis did not reflect the continuing controversy over the relative potency of different types of asbestos or the substantial latency period for asbestos-caused cancer. ${ }^{44}$

Finally, these RIAs were not blueprints for EPA regulatory action. EPA's actual regulatory decision reflected policy goals that deviated from the most efficient policy choices identified by the regulatory analysis. In the case of asbestos, EPA's regulatory strategy appears to have been directed toward eliminating the use of asbestos in products in general commerce, while exempting certain critical industrial and military applications of asbestos. As a result, EPA adopted a ban/phasedown of some general commerce product

40. In its final RIA, for example, EPA also reported a possible relationship between lead exposure and blood pressure. On the basis of this potential relationship, EPA calculated very large additional benefits - $\$ 38$ billion (present value) - associated with the estimated reduction in heart disease and strokes linked with the decline in blood pressure with the phasedown of lead gasoline. Final Lead RIA E12 (cited in note 25).

41. The shift to unleaded gas over the last five years has largeiv occurred as a result of the E.PA phasedown regulation. But in the early $1980 \mathrm{~s}$, a significant portion of the auto fleet was using leaded gas, even though-according to EPA's analysis-they would have been better off using unleaded gas. Id at 14, I8. There are two possible explanations: (1) consumers were poorly informed or (2) EPA's estimates of the benefits of using unleaded gas were too high.

42. Final Asbestos RIA, Part V (cited in note 35).

43. Id at Part VII.

44. See B. T. Mossman, et al, Asbestos: Scientific Developments and Implications for Public Policy, Science 247, 294-301 ( Jan 19, 1990). There were alternative estimates of potency available to EPA. Arguably, EPA chose conservative estimates to be cautious. But these upper-bound risk estimates were presented, without qualification, as representing the risk associated with asbestos use. Final Asbestos RIA, Part V and App D, Risk Models (cited in note 35). 
categories where the estimated health risks of continued use appear to be small and the opportunity costs of banning use appear to be substantial. ${ }^{45}$ This is particularly the case, for example, with EPA's ban/phasedown of asbestos use in asbestos cement pipe.

\section{V \\ Conclusion}

The requirement that EPA carry out a comprehensive analysis of its major regulatory proposals is controversial. Critics object to using "net social benefits" as the criterion for regulatory decisionmaking. Some even argue against the adoption of an analytical framework to assess of the tradeoffs that arise in setting environmental policy. ${ }^{46}$

An essential task of government, however, is to ask how and to what extent regulatory intervention will enhance the public welfare. Environmental regulation redirects substantial private resources for public purposes. It is the responsibility of government to assure that such intervention will achieve its objectives as efficiently and effectively as possible. Both economic analysis and benefit/cost analysis are vital to this process; they identify alternative approaches and provide decisionmakers with insight into the likely effects of these alternatives.

The better RIAs, as illustrated by the two case studies discussed above, can make a major contribution to the decisionmaking process. In these two examples, the RIAs led to changes in policy yielding substantial net social benefits. A number of EPA's RIAs, though, have not provided the analysis required by Executive Order 12291. The most common problems with these RIAs are that they fail to consider suitable alternatives to the selected regulatory action, and they fail to quantify benefits. This is a problem, unfortunately, that is shared with other federal agencies.

Because of the unevenness in the quality of the RIAs produced by all federal agencies-not just EPA-OMB published guidelines for developing RIAs as a part of the 1990-91 Regulatory Program. ${ }^{47}$ The new OMB guidelines and OMB efforts under Executive Order 12291 will not be sufficient, however, to improve federal agency analysis of proposed regulatory actions. These measures will need to be supplemented by institutional changes within the agencies so that decisionmakers are provided with the analysis required to make effective and efficient regulatory decisions.

45. 40 CFR $§ 763(1990)$.

46. See Steve Kelman, Cost-Benefit Analysis: An Ethical Critique, 5 Regulation 33-40 (Jan/Feb 1981).

47. Regulatory Program of the United States Government, April 1, 1990-March 31, 1991, App $\mathrm{V}$ at $653(\mathrm{OMB})$ 
